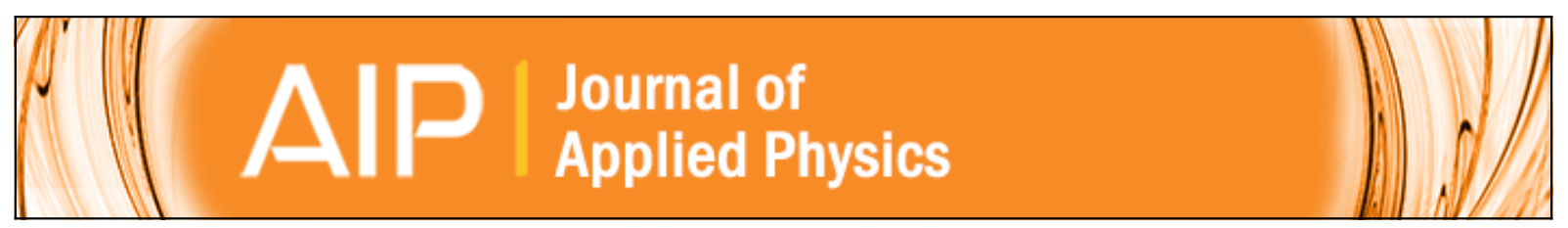

Influence of reactive atmosphere on properties of cobalt ferrite thin films prepared using pulsed-laser deposition
A. Raghunathan, D. C. Jiles, and J. E. Snyder

Citation: Journal of Applied Physics 109, 083922 (2011); doi: 10.1063/1.3574918

View online: http://dx.doi.org/10.1063/1.3574918

View Table of Contents: http://scitation.aip.org/content/aip/journal/jap/109/8?ver=pdfcov

Published by the AIP Publishing

Alp Re-register for Table of Content Alerts 


\title{
Influence of reactive atmosphere on properties of cobalt ferrite thin films prepared using pulsed-laser deposition
}

\author{
A. Raghunathan, ${ }^{\text {a) }}$ D. C. Jiles, and J. E. Snyder \\ Wolfson Centre for Magnetics, Cardiff University, Cardiff CF24 3AA, United Kingdom
}

(Received 25 October 2010; accepted 10 March 2011; published online 21 April 2011)

\begin{abstract}
A series of cobalt ferrite (CFO) thin films were grown on $\mathrm{SiO}_{2} / \mathrm{Si}(100)$ substrates using pulsedlaser deposition (PLD) at substrate temperature $\left(T_{\mathrm{DEP}}\right)$ of $250{ }^{\circ} \mathrm{C}$ and oxygen pressures $\left(P_{\mathrm{O} 2}\right)$ from 0.67 to $6.7 \mathrm{~Pa}$. The influence of $\mathrm{P}_{\mathrm{O} 2}$ on crystal structure, phase mixture, deposition rate, and magnetic properties was investigated. It is shown in this study that there is a window of $\mathrm{P}_{\mathrm{O} 2}$ for optimized growth of nanograined $\mathrm{CFO}$ films at low $T_{\mathrm{DEP}}$ and that either higher or lower values of $\mathrm{P}_{\mathrm{O} 2}$ produce undesirable multiphase mixtures. $\mathrm{CFO}$ films grown at such low substrate temperature and optimized oxygen pressure on thermal expansion matched substrates can be applied in multilayer sensors or MEMS devices. (C) 2011 American Institute of Physics.
\end{abstract} [doi:10.1063/1.3574918]

\section{INTRODUCTION}

Ferrite thin films are used extensively in microwave magnetic devices. ${ }^{1}$ Recently magnetoelastic ferrites have sparked considerable research interest to explore the potential for sensor applications. ${ }^{2}$ The growth of ferrite thin films ranges from nano- or polycrystalline to epitaxial using techniques such as spin-spray coating, electroplating, sputtering, pulsed-laser deposition, evaporation, and molecular beam epitaxy. Due to the complexity of the crystal structure of ferrites, structural disorders such as cation vacancies, oxygen deficiencies, nonequilibrium cation distributions, and grain boundaries influence the magnetic and electronic properties of the films. ${ }^{3}$ Cobalt ferrite (CFO), a partially inverse spinel structure ferrite, is unique among spinel ferrites due to its large magnetic anisotropy along with large anisotropic magnetostriction. The first order magnetocrystalline anisotropy constant $\left(\mathrm{K}_{1}\right)$ of $\mathrm{CFO}$ is positive, meaning the easy axes are along the (100) directions, and is an order of magnitude greater than other spinel structure ferrites. ${ }^{4}$

In our recent work, ${ }^{5}$ we reported the growth and properties of CFO thin films deposited at different $T_{\mathrm{DEP}}$ ranging between 250 and $600{ }^{\circ} \mathrm{C}$ in a reactive oxygen environment at $P_{\mathrm{O} 2}=2.93 \mathrm{~Pa}$ (22 mTorr). To completely optimize the growth of $\mathrm{CFO}$ on $\mathrm{SiO}_{2} / \mathrm{Si}$ substrates at a particular $T_{\mathrm{DEP}}$, it is necessary to study the properties of CFO thin films at various $P_{\mathrm{O} 2}$. Because high substrate temperatures limit the potential use of cobalt ferrite in MEMS devices and multilayer hybrid sensors, the lowest value of $T_{\mathrm{DEP}}\left(=250^{\circ} \mathrm{C}\right)$ from our previous study was chosen.

\section{THIN FILM GROWTH}

The films for this study were deposited from a $\mathrm{CoFe}_{2} \mathrm{O}_{4}$ target using a $248 \mathrm{~nm} \mathrm{KrF}$ excimer laser at $210 \mathrm{~mJ}$ and 13 $\mathrm{Hz}$ repetition rate. The laser spot size was $9 \times 1.5 \mathrm{~mm}$. The target-to-substrate distance was maintained at $5 \mathrm{~cm}$. Substrates were $\mathrm{Si}(100)$ wafers with $300 \mathrm{~nm}$ thermal $\mathrm{SiO}_{2}$ on

\footnotetext{
a) Author to whom correspondence should be addressed. Electronic mail: arunkumarr@cardiff.ac.uk.
}

top. The chamber was pumped down to $1.33 \times 10^{-5} \mathrm{~Pa}$ $\left(1 \times 10^{-7}\right.$ Torr $)$ before deposition. The substrate was maintained at a temperature of $250{ }^{\circ} \mathrm{C}$ during depositions. Films were deposited in reactive oxygen environment. A series of five different values of $P_{\mathrm{O} 2}$ were investigated: 0.67 (5), 1.99 (15), 2.93 (22), 4.67 (35), and 6.7 (50) Pa (mTorr). All films were cooled to room temperature under their respective oxygen pressures.

\section{EXPERIMENTAL}

Film thicknesses were measured from cross-sections in the scanning electron microscope (SEM). Crystal structure and orientation were investigated by $\theta-2 \theta$ x-ray diffraction (XRD) scans using $\mathrm{Cu} \mathrm{K} \alpha$ radiation. Composition was determined by energy-dispersive $x$-ray spectroscopy (EDX) in the SEM averaging over 15 locations. Magnetic hysteresis loops were measured at room temperature using a vibrating sample magnetometer (VSM) with maximum applied field of $1500 \mathrm{kA} / \mathrm{m}$ (20 kOe). Surface morphology and roughness of the deposited films were determined by atomic force microscopy (AFM). The imaging of magnetic domains in the films was carried out using magnetic force microscopy (MFM) with phase detection.

\section{RESULTS AND DISCUSSION}

\section{A. Crystallography}

The XRD scans of CFO thin films deposited at various oxygen pressures are shown in Fig. 1. The films deposited at 2.93 and $4.67 \mathrm{~Pa}$ appeared to be single phase with cubic spinel structure, whereas the films grown at $\mathrm{P}_{\mathrm{O} 2}$ lower than 2.93 $\mathrm{Pa}(0.67$ and $1.99 \mathrm{~Pa})$ were mixed phase. This is probably due to the formation of cobalt-rich $(\mathrm{Co}, \mathrm{Fe}) \mathrm{O}$ and iron-rich $\mathrm{Fe}_{2} \mathrm{O}_{3}$ phases in the film. A similar observation of secondary phase was made in bulk cobalt ferrite material when vacuum-annealed. ${ }^{6}$ It is known that at higher $P_{\mathrm{O} 2}$, the ablated species can reactively collide with ambient oxygen forming clusters. ${ }^{7}$ Hence deposition of thin films at high $P_{\mathrm{O} 2}$ and low substrate temperatures (in this case, $250^{\circ} \mathrm{C}$ ) could result in iron oxide and cobalt oxide clusters, causing iron oxide and 


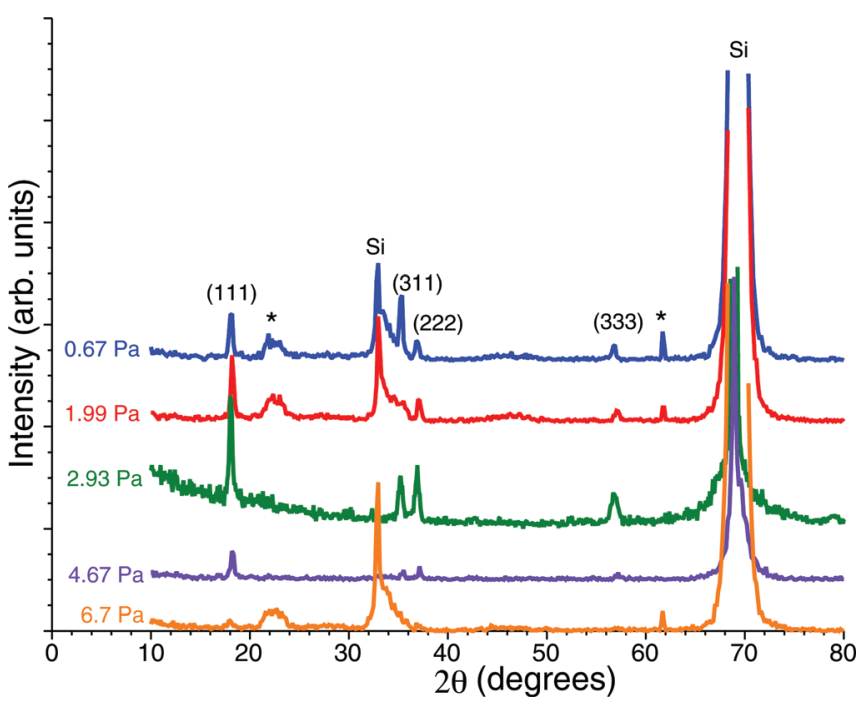

FIG. 1. (Color online) XRD patterns of cobalt ferrite films deposited at different oxygen pressures (* indicates secondary phases).

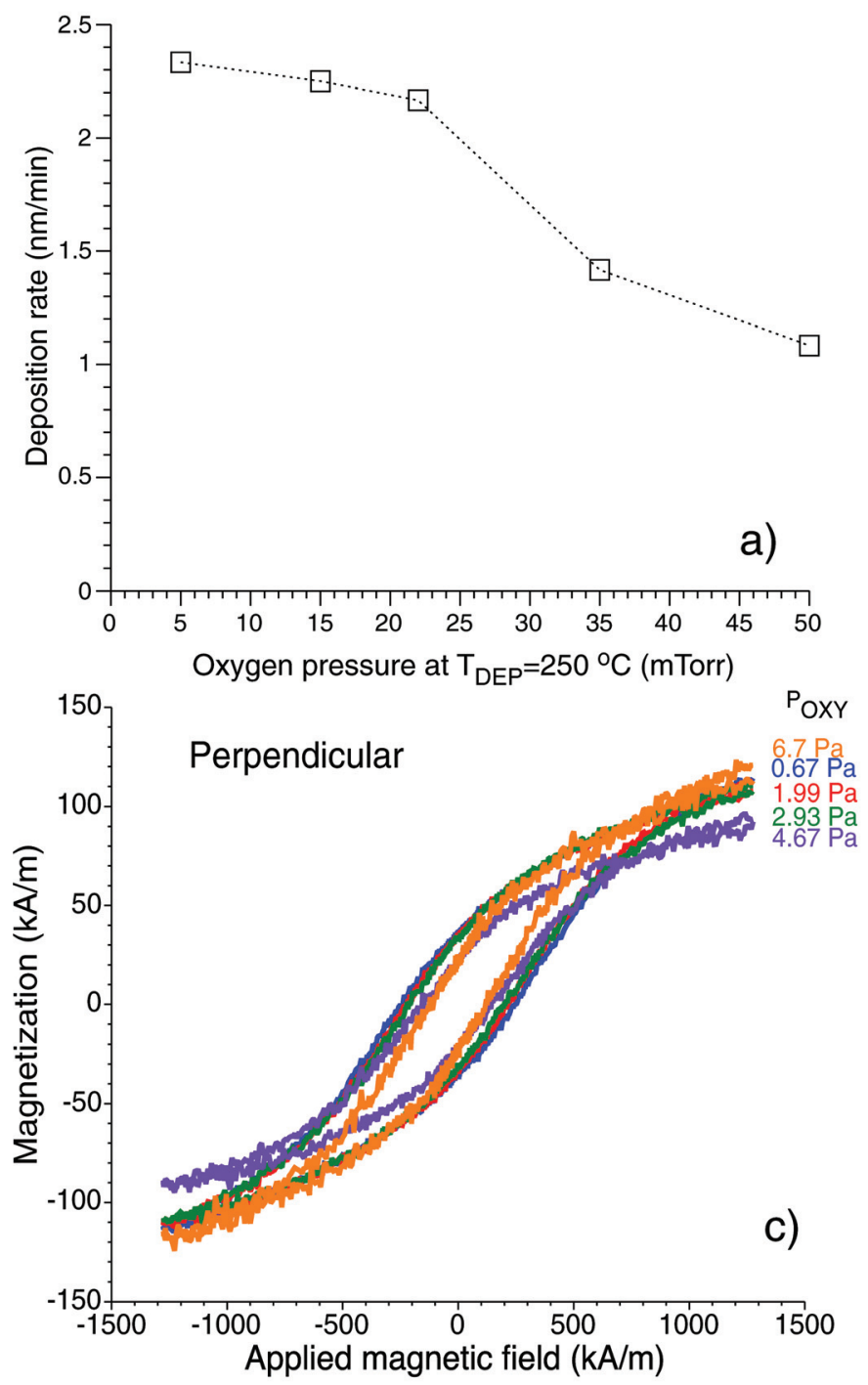

cobalt oxide regions in the film with insufficient ionic mobility to uniformly intermix them. Thus the sample deposited at high $P_{\mathrm{O} 2}$ also shows several structural phases, although the cation compositions of the phases could be considerably different from that formed at low $P_{\mathrm{O} 2}$.

\section{B. Composition}

From EDX, the average composition of all thin films was found to be $\mathrm{Co}_{1.1} \mathrm{Fe}_{1.9} \mathrm{O}_{4}$. The compositions of the different phases in the mixed-phase samples could not be determined as the regions of the different phases were not distinguishable in the SEM image. This is not surprising, as the region that is sampled by EDX in the SEM is $\sim 1 \mu \mathrm{m}$ dimension, whereas the grain size in these films is $\sim 25 \mathrm{~nm}$.

\section{Deposition rate}

The deposition rate of the PLD system mainly depends on the orientation and directivity of the laser plume at any given laser energy density. Figure 2(a) shows that the
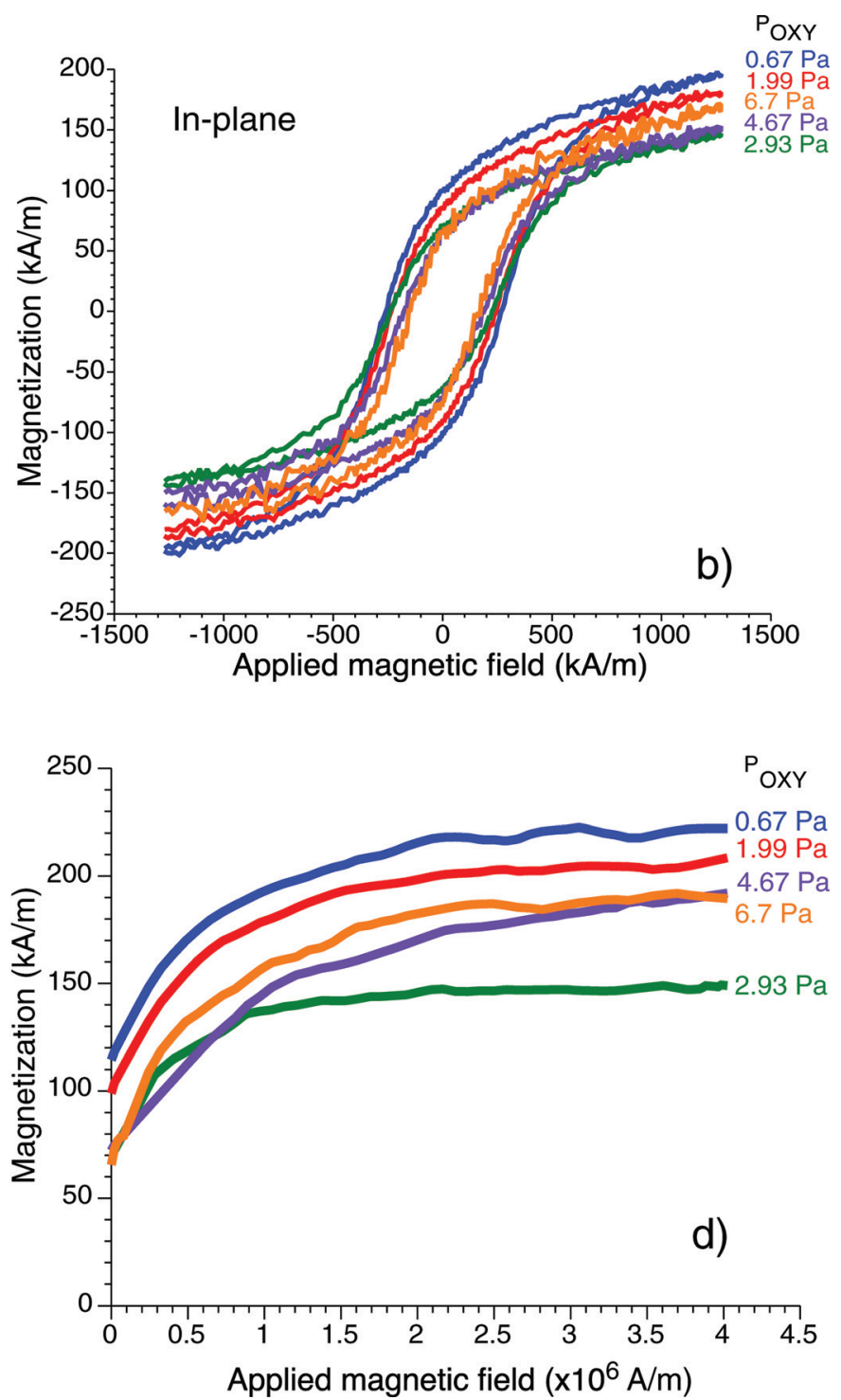

FIG. 2. (Color online) (a) Deposition rate as a function of $P_{\mathrm{O} 2}$ (b) in-plane and (c) perpendicular hysteresis loops of cobalt ferrite thin films deposited at $250^{\circ} \mathrm{C}$ and various oxygen pressures (d) initial magnetization curves measured from SQUID magnetometer. 


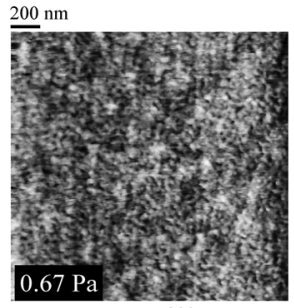

$200 \mathrm{~nm}$

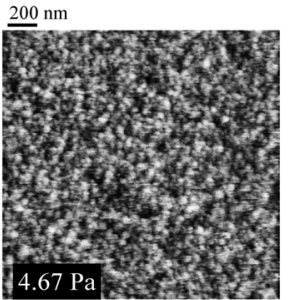

a)
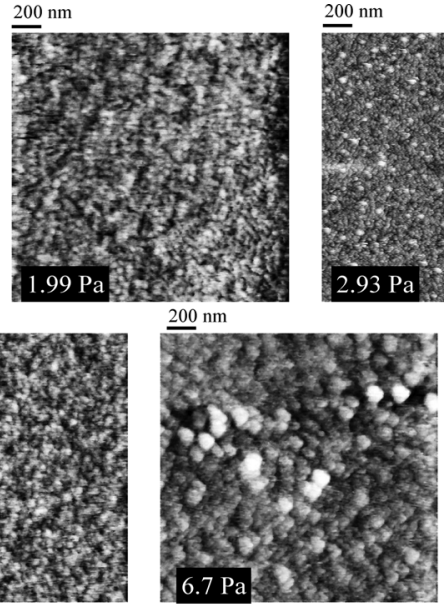

$200 \mathrm{~nm}$

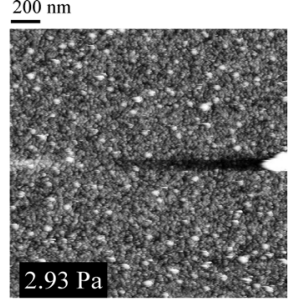

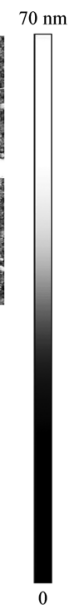

b)

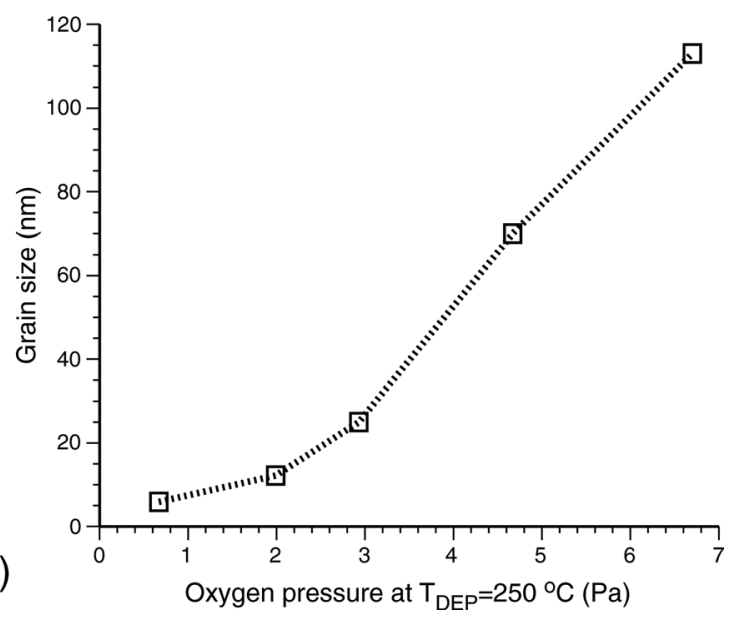

FIG. 3. (a) AFM images of cobalt ferrite samples deposited at various oxygen pressures and (b) variation of grain size with reactive oxygen pressure. The grain size increases with oxygen pressure.

deposition rate decreases rapidly after $2.93 \mathrm{~Pa}$. This observation is consistent with the study reported in the literature that showed that the laser plume broadens due to collisions between ejected species and ambient oxygen at $P_{\mathrm{O} 2}$ above $2.93 \mathrm{~Pa}^{8}$ These collisions also reduce the mean free path of the ejected species and hence enable particulate formation even before they reach the substrate.

\section{Magnetic properties}

The in-plane and perpendicular hysteresis loops of cobalt ferrite thin films deposited at different $P_{\mathrm{O} 2}$ were measured in the VSM and are shown in Figs. 2(b) and 2(c), respectively. The magnetic properties show a high perpendicular anisotropy due to thermal expansion mismatch between the film and the substrate (see Ref. 5 for discussion).

The initial magnetization curves measured from SQUID magnetometer, shown in Fig. 2(d), indicate that the mixedphase films show higher saturation magnetization than sin- gle-phase films. This may be attributed to the cation site occupancies and distribution among the phases in the films. Although none of $\mathrm{CoO}, \mathrm{FeO}$, or $\alpha-\mathrm{Fe}_{2} \mathrm{O}_{3}$ themselves are expected to contribute significant moment at room temperature, to the extent that $\mathrm{Co}$-rich $(\mathrm{Co}, \mathrm{Fe}) \mathrm{O}$ forms, it leaves behind an Fe-rich material, and the $\mathrm{Fe}$-rich spinel phase will have a higher moment than $\mathrm{CoFe}_{2} \mathrm{O}_{4}$ because $\mathrm{Fe}^{3+}$ ions have moments of $5 \mu_{\mathrm{B}}$, whereas $\mathrm{Co}^{2+}$ have moments of $3 \mu_{\mathrm{B}}$. Also to the extent that the films deposited at very low $(0.67$ and $1.99 \mathrm{~Pa})$ and very high $(6.7 \mathrm{~Pa}) P_{\mathrm{O} 2}$ are cobalt-rich in their tetrahedral sites (A-sites), then an increase in magnetization would be expected as the magnetic moment of a spinel is the difference of moments between the octahedral and tetrahedral sublattices.

\section{E. Surface morphology and domain imaging}

Figure 3(a) shows surface morphology of cobalt ferrite thin films deposited at different reactive oxygen pressures as seen in AFM. The RMS surface roughness was found to be
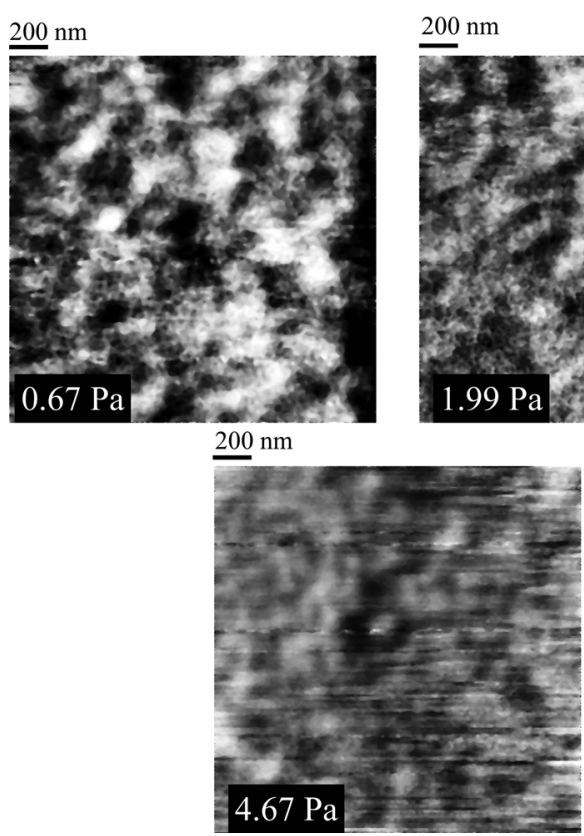
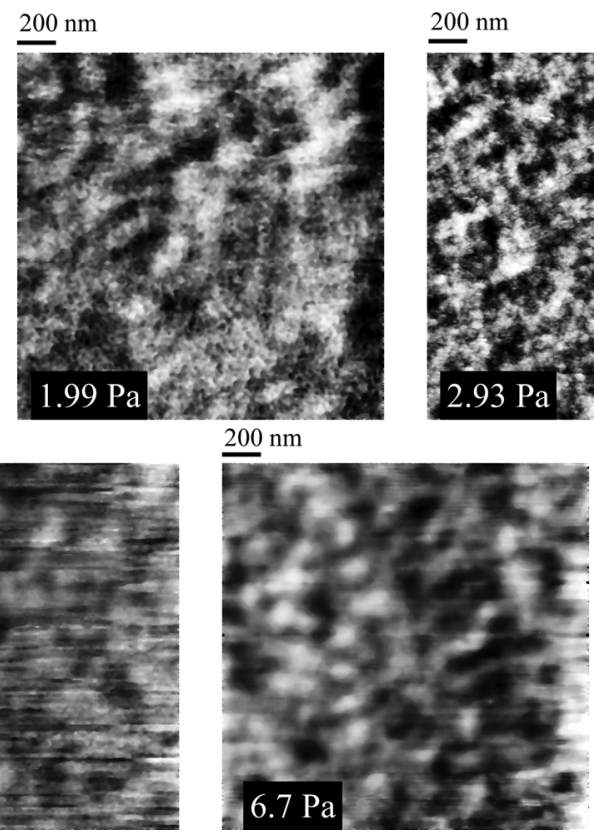
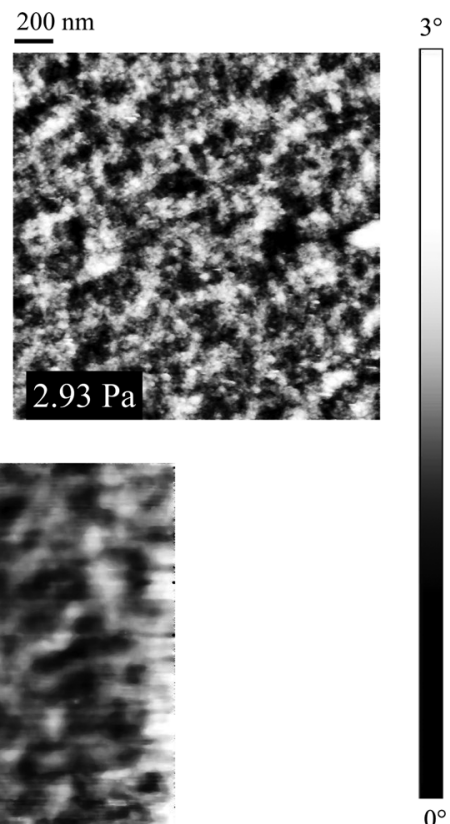

FIG. 4. MFM images of cobalt ferrite samples deposited at various oxygen pressures. The clusterlike magnetic domains are commonly found in high perpendicular anisotropy materials with large coercivity (Ref. 9). 
around $3 \mathrm{~nm}$ for all samples. The grain size increases with increasing $P_{\mathrm{O} 2}$ as shown in Fig. 3(b) from about $6 \mathrm{~nm}$ for $P_{\mathrm{O} 2}=0.67 \mathrm{~Pa}$ to about $115 \mathrm{~nm}$ for $P_{\mathrm{O} 2}=6.7 \mathrm{~Pa}$. The grain size increased drastically for values of $P_{\mathrm{O} 2}>2.93 \mathrm{~Pa}$. This could be related to the decrease in deposition rate at higher $P_{\mathrm{O} 2}$. At lower deposition rates, a longer time is allowed for the mobility of ions, which would enhance the growth of crystallites. It might also be related to the dependence of nucleation and crystal growth rates on the relative fluxes of depositing cations and oxygen.

Figure 4 shows the magnetic domain images of cobalt ferrite films deposited at various $P_{\mathrm{O} 2}$ as seen in MFM. The magnetic domains look like clusters. The clusterlike magnetic domains are commonly found in high perpendicular anisotropy materials with large coercivity. ${ }^{9}$

It should be noted from the preceding analysis that for the optimized growth of single-phase CFO films at low substrate temperatures, the reactive oxygen pressure should be chosen in the range between $2.67 \mathrm{~Pa}(20 \mathrm{mTorr})$ and $5.33 \mathrm{~Pa}$ (40 mTorr).

\section{CONCLUSIONS}

Cobalt ferrite thin films were grown on $\mathrm{SiO}_{2} / \mathrm{Si}(100)$ substrates using the pulsed-laser deposition at a substrate temperature of $250{ }^{\circ} \mathrm{C}$ and at a series of oxygen pressures, ranging from 0.67 to $6.7 \mathrm{~Pa}$. It was shown in this study that there is a window of oxygen pressure for optimized growth of nanograined cobalt ferrite films at low substrate temperatures. The growth of cobalt ferrite thin films at lower temperatures opens up possibilities of these thin film materials to be integrated with a wider range of multilayer device structures and MEMS devices.

\section{ACKNOWLEDGMENTS}

This research was supported by the Royal Society under the Wolfson Merit Scholarship award and by Cardiff School of Engineering.

${ }^{1}$ X. X. Xi, H.-C. Li, W. Si, A. A. Sirenko, I. A. Akimov, J. R. Fox, A. M. Clark, and J. Hao, J. Electroceram. 4, 393 (2000).

${ }^{2}$ J. A. Paulsen, A. P. Ring, C. C. H. Lo, J. E. Snyder, and D. C. Jiles, J. Appl. Phys. 97, 044502 (2005).

${ }^{3}$ J. Smit and H. P. J. Wijn, Ferrites, (N. V. Philips, Eindhoven, 1959).

${ }^{4}$ Y. Suzuki, Annu. Rev. Mater. Sci. 31, 265 (2001).

${ }^{5}$ A. Raghunathan, I. C. Nlebedim, D. C. Jiles, and J. E. Snyder, J. Appl. Phys. 107, 09A516 (2010).

${ }^{6}$ I. C. Nlebedim, N. Ranvah, P. I. Williams, Y. Melikhov, F. Anayi, J. E. Snyder, A. J. Moses, and D. C. Jiles, J. Magn. Magn. Mater. 321, 2528 (2009).

${ }^{7}$ X. Y. Chen, S. B. Xiong, Z. S. Sha, and Z. G. Liu, Appl. Surf. Sci. 115, 279 (1997).

${ }^{8}$ A. A. Gorbunov and V. I. Konov, Surf. Coat. Technol. 47, 503 (1991).

${ }^{9}$ A. Hubert and R. Schafer, Magnetic Domains, (Springer, New York, 1998). 